\title{
Drugs for Non-alcoholic Steatohepatitis (NASH): Quest for the Holy Grail
}

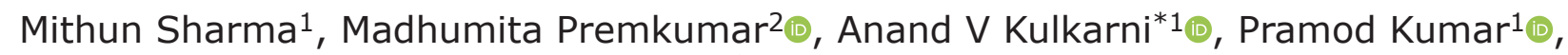 \\ D Nageshwar Reddy ${ }^{3}$ and Nagaraja Padaki Rao ${ }^{1}$ \\ ${ }^{1}$ Department of Hepatology, Asian Institute of Gastroenterology, Hyderabad, India; ${ }^{2}$ Department of Hepatology, PGIMER, \\ Chandigarh, India; ${ }^{3}$ Department of Gastroenterology, Asian Institute of Gastroenterology, Hyderabad, India
}

\begin{abstract}
Nonalcoholic fatty liver disease (NAFLD) is a global epidemic that is likely to become the most common cause of chronic liver disease in the next decade, worldwide. Though numerous drugs have been evaluated in clinical trials, most of them have returned inconclusive results and shown poorlytolerated adverse effects. None of the drugs have been approved by the Food and Drug Administration for treating biopsy-proven non-alcoholic steatohepatitis (NASH). Vitamin $\mathrm{E}$ and pioglitazone have been extensively used in treatment of biopsy-proven nondiabetic NASH patients. Although some amelioration of inflammation has been seen, these drugs did not improve the fibrosis component of NASH. Therefore, dietary modification and weight reduction have remained the cornerstone of treatment of NASH; moreover, they have shown to improve histological activity as well as fibrosis. The search for an ideal drug or 'Holy Grail' within this landscape of possible agents continues, as weight reduction is achieved only in less than $10 \%$ of patients. In this current review, we summarize the drugs for NASH which are under investigation, and we provide a critical analysis of their up-to-date results and outcomes.
\end{abstract}

Citation of this article: Sharma M, Premkumar M, Kulkarni AV, Kumar P, Reddy DN, Rao NP. Drugs for non-alcoholic steatohepatitis (NASH): Quest for the holy grail. J Clin Transl Hepatol 2021;000(000):000-000. doi: 10.14218/JCTH.2020. 00055.

\section{Introduction}

Nonalcoholic fatty liver disease (NAFLD) is an emerging global epidemic. It is the most common cause of chronic liver disease in the western world. ${ }^{1}$ The pooled prevalence of NAFLD in Asia is $30 \%$ (95\% confidence interval [CI]: 28.13-31.15). ${ }^{2}$ The term nonalcoholic steatohepatitis

Keywords: Fatty liver; NAFLD; NASH; Obeticholic acid; Saroglitazar.

Abbreviations: CI, confidence interval; FDA, Food and Drug Administration; FXR, farnesoid X receptor; NAFLD, nonalcoholic fatty liver disease; NASH, nonalcoholic steatohepatitis; OCA, obeticholic acid; PIVENS, pioglitazone versus vitamin $E$ versus placebo for the treatment of nondiabetic patients with nonalcoholic steatohepatitis; PPAR, peroxisome proliferator-activated receptor; TONIC, treatment of NAFLD in children; UDCA, ursodeoxycholic acid.

Received: 16 June 2020; Revised: 29 October 2020; Accepted: 12 November 2020

*Correspondence to: Dr. Anand V Kulkarni, Department of Hepatology and Liver Transplantation, Asian Institute of Gastroenterology, Hyderabad, India. Tel: 040-42444222, E-mail: anandvk90@gmail.com
(NASH) was coined almost 4 decades ago. ${ }^{3}$ Recently, NAFLD was renamed as "metabolic (dysfunction)-associated fatty liver disease", or "MAFLD". ${ }^{4}$ However, the change in terminology is unlikely to alter the management of these patients and hence will not be referred to in this manuscript. In this review, instead, we will focus on the drugs used for NASH. There have been several trials to find an ideal drug for the treatment of NASH. ${ }^{5-10}$ Despite several advances in the understanding of the pathophysiology underlying this common disease, to date, there are no drugs approved by the Food and Drug Administration (FDA) for the treatment of either simple steatosis or NASH. Recently, FDA has accepted a new drug application (not approved) for OCA, a farnesoid $X$ receptor (FXR) agonist, which was shown to improve fibrosis in NASH. ${ }^{11}$ In this review, we outline the mechanisms and targets of such, and discuss some of the major drug trials in NASH.

\section{Journey of drugs in NASH}

For the approval of a drug for a disease, it needs to undergo preclinical trials, followed by Phase 1 safety studies, which are supported by Phase 2 studies. Phase 2 studies are dosefinding trials and aid in evaluating efficacy of a drug. Once a drug is found to be effective, it undergoes Phase 3 studies that compare the safety and efficacy of the drug with existing therapies. Then, the drug is placed for review before an appropriate drug review committee that may/may not approve the drug. ${ }^{12}$ Post-approval, there are phase 4 trials, a strategy which is also known collectively as 'post-marketing surveillance'. The objective of the phase IV studies is to check the drug's performance in real-life scenarios, to study the long-term risks and benefits of the drug, and to discover any rare side effects. Interestingly, for each phase of the trial, there are recommended endpoints to be achieved before proceeding to the next stage of a trial in adult patients, such as those with NASH. ${ }^{13}$ However, there are no clear endpoints for pediatric NASH. ${ }^{13}$ For NASH, the endpoint for a phase 3 trial is NASH resolution (defined as disappearance of ballooning and disappearance or persistence of minimal, lobular inflammation that does not qualify for the diagnosis of NASH), with or without a reduction in fibrosis stage by one point. ${ }^{13}$

There are certain major hindrances to conducting a clinically relevant trial in NASH. ${ }^{14,15}$

Some of the limiting factors are:

1. Biopsies are required to define participants and are needed to establish efficacy, as well.

2. Many trials have high screen fail rate, due to stricter inclusion criteria.

3. There is often a high placebo response rate in the con- 


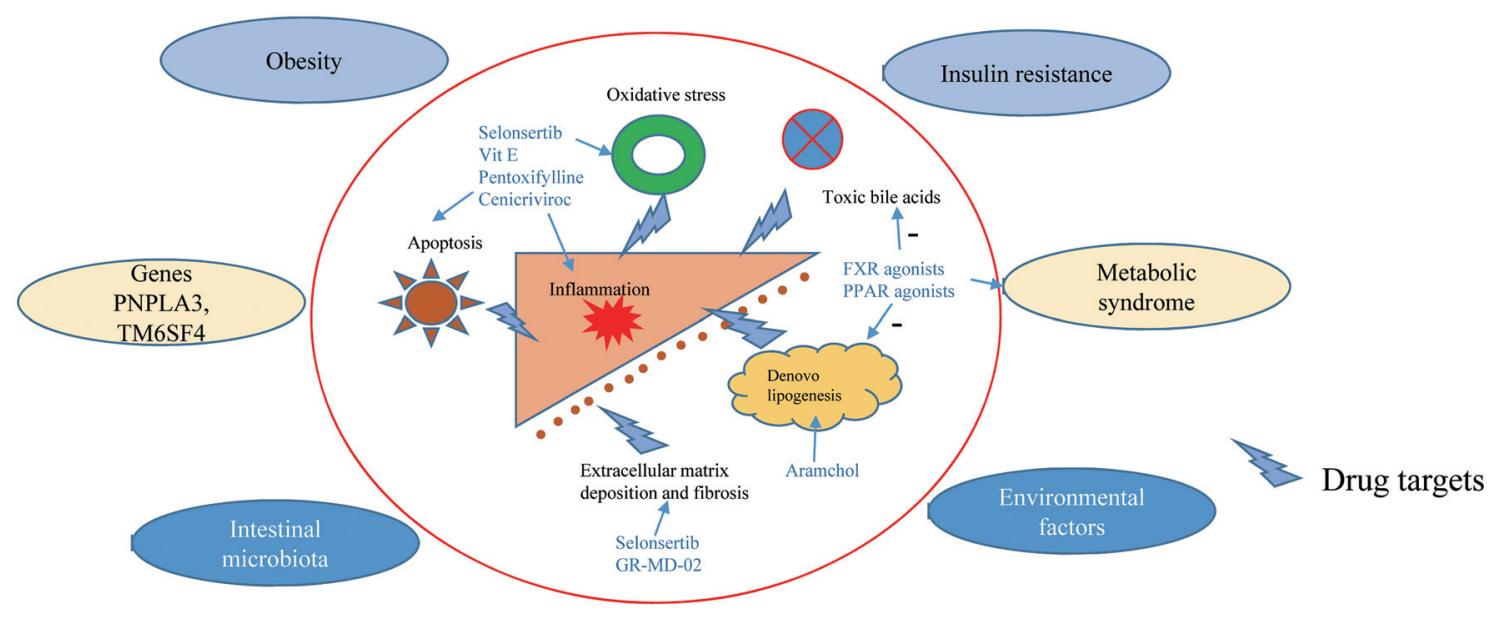

Fig. 1. Factors implicated in the pathogenesis of NASH and possible drug targets. The factors which lead to NAFLD are depicted in the outer circle, while the changes that occur inside the liver are shown within the red circle. The drug targets are shown in blue lightening arrows. Abbreviations: FXR, farnesoid X receptor; PNPLA, patatin-like phospholipase domain-containing protein A; PPAR, peroxisome proliferator-activated receptors; TM6SF4, transmembrane 6 superfamily 2 human gene; Vit E, vitamin E.

trol group. The reasons for this are unclear but may be due to behavioral changes in the control group, resulting in weight loss.

4. Most of the studies use two primary endpoints. 4a. Improvement in fibrosis, with no worsening of NASH 4b. NASH resolution without worsening of fibrosis

5. Challenges in developing clinical endpoints, due to the lack of specific symptoms of NASH.

6. Difficulties in managing confounders, such as recording alcohol intake before and during the study, and the lack of uniformity in diet and physical activity.

\section{Histopathology and grading of NASH}

There are two major grading systems of NASH. One which is frequently used in clinical trials is NAFLD Activity ScoreClinical Research Network (NAS-CRN) and has been validated to compare the biopsies. NAS-CRN consists of three components of activity, viz. steatosis (score $0-3$ ), lobular inflammation (score 0-3), and ballooning (score 0-2), with a maximum score of 8 . A score $\geq 5$ suggests definite NASH. Fibrosis is graded from 0-4 ( 0 : no fibrosis to 4 : cirrhosis) ${ }^{16}$ NAS-CRN has been validated in both children and the adult population. The Steatosis activity fibrosis (SAF) scoring system aids in the diagnosis of NASH and can be used in clinical trials. ${ }^{17}$ The SAF score is semi-quantitative and differs slightly from the NAS-CRN, with lobular inflammation scored from 0 to 2 (instead of 3 ) and ballooning from 0-2 (1: clusters, reticulated cytoplasm; 2: enlarged hepatocytes, as opposed to few and many in NAS-CRN scoring). As the final score is meant to represent a diagnosis, steatosis must be $>0$, wherein activity (ballooning plus lobular inflammation) must be $\geq 2$, in which ballooning is at least 1 . Fibrosis is based on the NASH-CRN scale and is reported as " $F$ ".

\section{Pathogenesis and targets}

To find an ideal drug for NASH, it is essential to understand its pathogenesis and identify a single ideal target. The target may exist at multiple levels and may also be outside the liver itself. Whether NAFLD is the 'hepatic manifestation' of metabolic syndrome or a pathogenic determinant of metabolic syndrome is still unknown. ${ }^{18,19}$ However, there is a growing body of evidence strongly supporting the notion that NAFLD precedes the development of type 2 diabetes mellitus (T2DM) and metabolic syndrome. ${ }^{18,20}$ It is also a paradox to find out if the drugs that is appropriate for lean and obese NASH patients would be similar. An ideal drug for NASH would be a drug that targets fat deposition, has antiinflammatory and antifibrotic properties, and reduces cardiovascular risk, which is the most frequent cause of mortality in NASH.21,22 The pathogenesis of NAFLD is complex, involving extrinsic predisposing factors and intrinsic genetic factors. ${ }^{23}$ Insulin resistance, however, remains central to the development of NAFLD. The complex interplay of different factors in pathogenesis is shown in Fig. 1.

Currently, drug treatment is indicated for patients with progressive NASH (i.e. NASH activity with bridging fibrosis/cirrhosis), early-stage NASH (at high risk for disease progression; age >50 years, metabolic syndrome, diabetes mellitus or increased alanine transaminase), or NASH with high necroinflammatory activity. 24,25 Most of the pharmacotherapy trials have been carried out in biopsy-proven $\mathrm{NASH}$ patients (biopsy is must to prove NASH/inflammation). Several drugs have shown initial promise but failed to meet the critical endpoint of improvement in fibrosis scores. The drugs and modalities of treatment that have been tried in patients with NASH are discussed below.

\section{Lifestyle changes for the treatment of NASH}

The most effective and proven therapy for NASH is weight loss. Analysis of data from eight randomized control trials has shown that $>5 \%$ weight loss leads to resolution hepatic steatosis, and $\geq 7 \%$ improves the inflammatory score of NAS (NAFLD activity score). ${ }^{26}$ But, reportedly, only $50 \%$ of patients can achieve a weight loss of $7 \% .27$ Lastly, a weight loss of $\geq 10 \%$ results in the resolution of early fibrosis, in approximately $45 \%$ of subjects. ${ }^{27}$

Physical activity of $\geq 150 \mathrm{~m} /$ week is associated with improvement in liver enzymes, irrespective of the weight loss. More than 8,000 steps per day is associated with a reduction in all-cause mortality; however, the number of steps required for reduction in NAS score/liver enzymes has not been evaluated. 28 


\section{Dietary interventions}

A triple hit behavioral phenotype exists, which involves i) sedentary behavior, ii) low physical activity, and iii) poor diet, all of which are well known to be associated with poor cardio-metabolic health, NAFLD, and overall mortality. ${ }^{29}$ Along with physical activity, a healthy diet is recommended for NAFLD patients. ${ }^{24}$ Refined sugar and sugar-sweetened beverages are a common source of empty calories. ${ }^{29}$ These fructose-rich diets increase the hepatic synthesis of triglycerides. Hence, sugar-sweetened beverages should be avoided. Mediterranean diet is primarily plant-based (whole grains, legumes, fruit, vegetables), low in carbohydrates (limited simple sugars and refined carbohydrates), and rich in monounsaturated (mostly olive oil) and omega-3 fats, and which incorporates limited red meat, ad low-fat dairy products, which has been shown to improve the hepatic steatosis and insulin resistance and is the recommended diet for NAFLD. ${ }^{30,31}$ Recent studies have shown that 1 year of a hypocaloric ( $750 \mathrm{Kcal} /$ day) diet combined with $200 \mathrm{~m}$ of exercise per week has a dose relationship with weight loss and leads to improvement in NASH, including fibrosis. ${ }^{27}$ The combination of a hypocaloric diet (reduction by $500-1,000$ $\mathrm{kcal} /$ day) and moderate-intensity exercise would provide the best likelihood of sustaining weight loss over time. ${ }^{24}$ Currently, the time-tested diet and exercise therapy remains the most effective and cost saving intervention for management of NAFLD.

\section{Drugs}

\section{Antioxidants}

Vitamin $\mathrm{E}$

Vitamin E has been studied in the landmark PIVENS (adult patients) and TONIC trials (pediatric population), where the antioxidative and free radical scavenging property of vitamin $\mathrm{E}$ has been hypothesized to improve NASH. ${ }^{6,8}$ Indeed, there was a significant improvement in steatosis and inflammation in patients treated with vitamin E for 96 weeks compared to placebo. ${ }^{6}$ However, there was no improvement in fibrosis. ${ }^{6}$ There have been conflicting reports on the rise in all-cause mortality in patients receiving vitamin E. 32,33 However, a small increase in prostatic cancer due to long term administration of vitamin $\mathrm{E}$ is known. ${ }^{34}$ Though the drug is well tolerated, the current guidelines recommend vitamin E (rrr-a-tocopherol) at a daily dose of $800 \mathrm{IU} /$ day in non-diabetic adults with biopsy-proven $\mathrm{NASH}$, weighing the risk-benefit ratio before initiation of treatment. ${ }^{24}$ The longterm safety of administration of vitamin $E$ for more than 6 months is unclear.

\section{Pioglitazone}

Pioglitazone, an agonist of peroxisome proliferator-activated receptor (PPAR) Y, was evaluated in the same PIVENS study. Pioglitazone has been hypothesized to increase the adipocyte uptake of fatty acids, thereby potentially drawing fat away from the hepatocytes. ${ }^{6}$ The use of $30 \mathrm{mg}$ of pioglitazone for 96 weeks in non-diabetic patients showed a significant improvement in NASH compared to placebo. However, there was no improvement in fibrosis. ${ }^{6}$ The major drawback of vitamin E and pioglitazone is the lack of improvement in fibrosis, which is an important determinant of outcomes in NASH. 35 Thus, the clinical relevance of the results from the PIVENS study is limited. Further, weight gain, bladder cancer, and bone loss are major concerns associated with pioglitazone. ${ }^{24}$ Of note, pioglitazone may be used for both diabetic and non-diabetic patients with biopsy-proven NASH only after explaining the risks and benefits in detail. 24,31

\section{Ursodeoxycholic acid (UDCA)}

UDCA at a dose of $13-15 \mathrm{mg} / \mathrm{kg}$ body weight in patients with biopsy-proven NASH has not shown any benefit when compared with placebo and is not recommended for NASH. ${ }^{7}$ Animal studies on a side-chain-shortened homologue of UDCA, nor- (n)UDCA, can attenuate the progression of $\mathrm{NASH} .{ }^{36} \mathrm{~A}$ recent human study (phase 2 trial) reported significant improvement in serum ALT levels at 12 weeks with the use of nUDCA at $1,500 \mathrm{mg}$ per day compared to placebo. ${ }^{37}$ Further phase III studies are required to confirm if the drug can meet the recommended endpoints.

Omega-3 fatty acids

Omega-3 fatty acids can reduce oxidative stress, lipotoxicity, and inflammation in patients with NASH. ${ }^{38}$ There have been conflicting reports about efficacy of omega-3 fatty acids in NAFLD. 10,39 The optimum dose has not yet been determined. However, the benefits of omega- 3 fatty acid supplementation have been noted with a dose of $\geq 0.83 \mathrm{~g} /$ day. ${ }^{40}$ Currently, they can be used to treat hypertriglyceridemia in NASH but not for the treatment of NAFLD or $\mathrm{NASH} .{ }^{24}$

\section{Metformin}

Early studies with metformin showed improvement of insulin resistance, liver chemistries, and a modest reduction in hepatic steatosis. ${ }^{41}$ Subsequently, two meta-analyses with the use of metformin in NASH showed no benefit and are currently not recommended for the treatment of $\mathrm{NASH} .42,43$

Pentoxifylline (PTX)

PTX inhibits several pro-inflammatory cytokines, including tumor necrosis factor (TNF)-a. ${ }^{44}$ PTX increases hepatic glutathione levels in mice with steatohepatitis induced by a methionine choline-deficient diet and reduces the production of oxygen radicals induced by prolonged ischemia time in rat livers. ${ }^{44,45}$ PTX down-regulates profibrogenic cytokines and procollagen I expression in a rat model of biliary duct occlusion. ${ }^{46}$ Although preclinical studies have demonstrated the efficacy of PTX in NASH, there are conflicting reports in human trials of PTX. ${ }^{45,47}$ PTX is currently not recommended for $\mathrm{NASH}$, due to insufficient evidence.

\section{Drugs in the pipeline for NASH}

The increasing burden of NASH worldwide has kept researchers astute to discover a new drug. NASH is associated with a high lifetime economic burden. In the absence of treatment, the total direct cost of illness for these patients will continue to grow. ${ }^{48}$ Several drugs are in the pipeline for the treatment of NASH. Although none of these drugs appear as ideal, many of them seem promising. Some of these drugs are detailed in Table 1. 
Table 1. Mechanism of novel therapies for NASH

\begin{tabular}{|c|c|c|c|}
\hline Name of drug & Mechanism of action & Phase of study & Comments \\
\hline OCA & FXR agonist & 3 & $\begin{array}{l}\text { Review with FDA for approval } \\
\text { likely in June } 2020\end{array}$ \\
\hline Elafibranor & PPARa $\delta$ agonist & 3 & $\begin{array}{l}\text { Missed primary endpoints } \\
\text { in } 2015 \text { and } 2020\end{array}$ \\
\hline Aramchol & $\begin{array}{l}\text { Stearoyl Co-A desaturase } 1 \text { inhibitor } \\
\text { and prevents de novo lipogenesis }\end{array}$ & 3 & $\begin{array}{l}\text { Results of the ARMOR } \\
\text { study are awaited }\end{array}$ \\
\hline Saroglitazar & Dual PPARay agonist & $\begin{array}{l}\text { Phase } 2 \text { studies in } \\
\text { USA and phase } 3 \\
\text { studies in India }\end{array}$ & $\begin{array}{l}\text { Currently approved by the DCGI. } \\
\text { Abstracts have shown more } \\
\text { effect on steatohepatitis. }\end{array}$ \\
\hline Cenicriviroc & $\begin{array}{l}\text { CCR2 and CCR5 chemokine } \\
\text { receptor antagonist }\end{array}$ & $\begin{array}{l}\text { CENTAUR study has } \\
\text { shown improvement }\end{array}$ & $\begin{array}{l}\text { Data from AURORA study are } \\
\text { expected by September } 2020\end{array}$ \\
\hline Emricasan & Pan-caspase inhibitor & Phase 2 & Did not meet the primary endpoint \\
\hline Belapectin & Galectin-3 inhibitor & $\begin{array}{l}\text { Phase } 2 \text { study on } \\
\text { effect in NASH and } \\
\text { fibrosis and reduction } \\
\text { of portal pressure }\end{array}$ & $\begin{array}{l}\text { No improvement in fibrosis } \\
\text { or portal hypertension }\end{array}$ \\
\hline $\begin{array}{l}\text { GLP-1 agonists: } \\
\text { liraglutide and } \\
\text { semaglutide }\end{array}$ & GLP-1 hormone & 3 & $\begin{array}{l}\text { Studies with semaglutide } \\
\text { hold promise and have shown } \\
\text { fibrosis improvement }\end{array}$ \\
\hline
\end{tabular}

Abbreviations: CCR, CC chemokine receptor; DCGI, Drugs Controller General of India; FDA, Food and Drug Administration; FXR, farnesoid X receptor; GLP, glucagonlike peptide, NAFLD, non-alcoholic fatty liver disease; NASH, non-alcoholic steatohepatitis; OCA, obeticholic acid; PPAR, peroxisome proliferator-activated receptors.

Obeticholic acid (OCA)

Bile acid signal receptors are abundant in the liver, kidney, adipose tissue, small intestine, and immune cells. ${ }^{49}$ OCA, 6a-ethyl chenodeoxycholic acid (INT 747), is a semi-synthetic derivative of chenodeoxycholic acid. It is a 100-times more potent agonist of FXR than chenodeoxycholic acid. 50,51 OCA is rapidly absorbed orally and reaches a peak plasma concentration in approximately 1.5 hours after intake and has a steady-state half-life of 4 days. The drug is not affected by food intake. The mean volume distribution of OCA is $618 \mathrm{~L}$ and is about $99 \%$ protein bound. The liver extensively metabolizes it into glycine and taurine conjugates. OCA undergoes extensive entero-hepatic circulation, and $>85 \%$ of metabolites are excreted in feces. FXR activation is mediated by binding of OCA to FXR receptors, which leads to increased secretion of FGF19 from the ileum. This results in formation of the $\beta$-klotho-FGF4-FGF19 complex, which inhibits CYP7A1 expression and bile acid synthesis. Besides, there is an increase in bile salt exporter protein (known as BSEP) and multidrug resistance 3 (known as MDR3) protein, promoting efflux of bile from hepatocytes. Further, OCA has a mild suppressive effect on the transforming growth factor-beta gene and extracellular matrix reorganization and stellate cell activation. The mechanism of action of OCA is summarized in Fig. 2.

The phase $2 \mathrm{~b}$ study of OCA in NASH, called the 'FLINT' study, showed a significant improvement of NAS score by $\geq 2$ points, without worsening of fibrosis, in $45 \%$ of patients receiving OCA at $25 \mathrm{mg}$, as compared with $21 \%$ in placebo $(p=0.0002)$. Thirty-five percent in the OCA group also showed improvement in fibrosis compared to $19 \%$ in the placebo group $(p=0.004) .{ }^{52}$ However, this study was terminated early due to administrative reasons. This was followed by a subsequent phase 3 study (the REGENERATE trial) involving 2,400 NASH patients with F2-3 fibrosis. They were randomized in $1: 1: 1$ ratio to receive either placebo or OCA at $10 \mathrm{mg}$ or OCA at $25 \mathrm{mg}$ per day for 48 weeks. ${ }^{53}$ An interim analysis at 18 months on 931 patients showed improvement in fibrosis by $\geq 1$ stage, with no worsening of
$\mathrm{NASH}$ in $23 \%$ of patients receiving OCA at $25 \mathrm{mg}$, when compared with $12 \%$ in the placebo arm $(p=0.0002)$ and $18 \%$ in the OCA $10 \mathrm{mg}$ group ( $p=0.04$ for placebo). ${ }^{11} \mathrm{~A}$ dose-dependent decrease in liver chemistries was observed from 3 months to 18 months. Similarly, improvement in NAS score by 2 points without worsening of fibrosis was significantly higher in the OCA $25 \mathrm{mg}$ group when compared to placebo ( $36 \%$ vs. $24 \% ; p=0.0012$ ), with no such difference between the OCA $10 \mathrm{mg}$ and placebo groups (30\% vs. 24\%; $p=0.11) .{ }^{11}$ Considering the vast number of NASH patients worldwide, this promising data would help to avoid many of the liver transplants attributable to NASH. Recent studies have shown that underlying genetic abnormalities may identify a cohort of patients who would respond to OCA.54

Pruritis and a rise in low-density lipoprotein cholesterol (LDL) are the two major concerns with the use of OCA. The most common side effect reported with OCA is pruritus. Pruritus on treatment was reported in $19 \%$ of patients on placebo compared to $28 \%$ with OCA at $10 \mathrm{mg}$ and $51 \%$ with OCA at 25 mg. ${ }^{11}$ Nearly $10 \%$ had to discontinue OCA (25 $\mathrm{mg}$ ) due to pruritis compared to $1 \%$ each in the OCA $10 \mathrm{mg}$ and placebo arms. ${ }^{11,55}$ The general concern for a physician is introducing pruritis in an asymptomatic disease. However, in a recent abstract, the interim analysis of the REGENERATE trial showed lower patient-reported outcomes than the general population on a specific questionnaire (the chronic liver disease questionnaire-NASH), and the patient-reported outcomes improved with OCA treatment. ${ }^{56}$ The authors further argued that pruritis is present in $21 \%$ of individuals at baseline, which is also unclear. Female gender, gastrointestinal comorbidity, and psychiatric comorbidity were associated with clinically important low itch score. However, data suggested that OCA-related pruritus occurs early in the treatment, without any subsequent worsening or negative impact on patientreported outcomes. Importantly, thus far, OCA is the only drug to have met the endpoint of fibrosis improvement.

Besides, OCA therapy increases small very low-density lipoprotein (VLDL) particles, large and small LDL particles, and reduces high-density lipoprotein particles at 12 weeks, which reverses after drug discontinuation. ${ }^{57}$ Whether this 


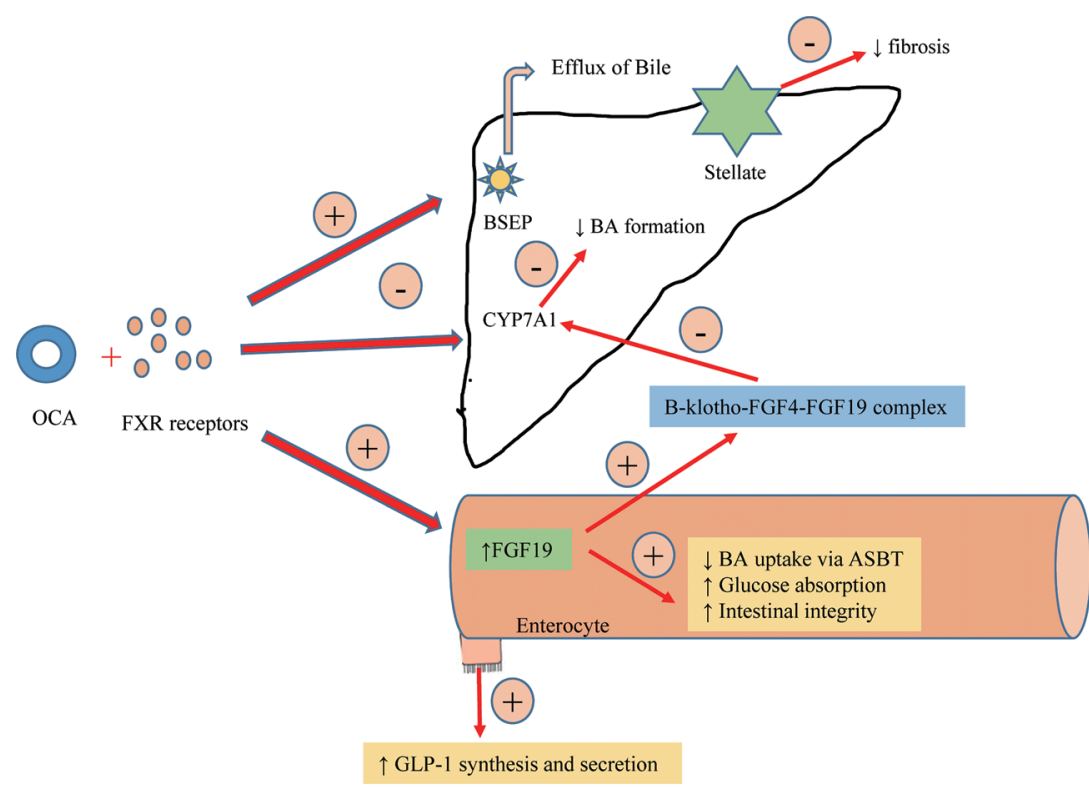

Positive effect

Negative effect

Fig. 2. Proposed mechanism of action of OCA in NASH. In the small intestine (orange cylinder) OCA binds to FXR receptors and through formation of the B-klotho-FGF4-FGF19 complex inhibits CYP7A1 and decreases bile acid synthesis. OCA increases the expression of the bile salt exporter protein BSEP and the multidrug resistance 3 protein MDR3, promoting efflux of bile from liver. OCA also decreases stellate cell (green star) activation, leading to decrease in fibrosis. OCA within the enterocytes leads to increased GLP-1 formation and improves insulin sensitivity. Abbreviations: ASBT, apical sodium-dependent bile acid transporter; BA, bile acid; CYP7A1, cytochrome P450 family 7 subfamily A member 1; FGF, fibroblast growth factor; GLP-1, glucagon-like peptide-1.

leads to an increased risk of cardiovascular mortality in NASH patients is not yet known. Concurrent use of statins (in the CONTROL trial) lowered the LDL cholesterol to below baseline as early as 4 weeks after initiation and has an acceptable tolerability profile. ${ }^{57}$ The FDA approved OCA in 2016 for use in primary biliary cholangitis at a dose of $5-10 \mathrm{mg} /$ day for nonresponders in Child $A$ cirrhotics and non-cirrhotics. While the recommended dose for Child B/C cirrhotics is $5 \mathrm{mg} /$ weekly, to a maximum dose of $10 \mathrm{mg}$ twice weekly. ${ }^{58}$

\section{PPAR agonists}

These are a group of nuclear receptor proteins that act as modulators of gene expression by functioning as transcription factors. 59 They have a role in lipid, protein and carbohydrate metabolism, as well as in cellular differentiation. Fibrates consist of fenofibrate, clofibrate, gemfibrozil, are PPARa agonists. They help in breakdown and transport of fatty acid and are found in abundance in the liver, skeletal muscle, and endothelial cells. ${ }^{60}$ Studies with fibrates in NASH did not show any difference in the improvement in either steatosis or fibrosis. ${ }^{61,62}$ A possible reason for their ineffectiveness in humans is because of the lower expression of PPARa in humans when compared to mouse models.

Thiazolidinediones (TZD), pioglitazone, and rosiglitazone are PPARy agonists. PPARy, which is mainly located in the adipose tissue, plays a vital role in the regulation of adipocyte differentiation, adipogenesis, and lipid metabolism. ${ }^{63}$ They have shown to improve glucose uptake and increase fatty acid oxidation, and insulin secretion, leading to improvement in insulin sensitivity. ${ }^{64}$ Pioglitazone, a weak PPARY agonist, showed a significant decrease in serum ALT and total hepatic lipid content and an increase in adiponectin expression in mouse models. ${ }^{65}$ In a trial of 55 patients with impaired glucose tolerance (or T2DM), pioglitazone administered with a hypocaloric diet improved steatosis and inflammation but not fibrosis. 66 Even in the PIVENS trial, there was no improvement in fibrosis. ${ }^{6}$ (Pioglitazone has been discussed in the previous paragraph). Rosiglitazone, a potent PPARy agonist, on the other hand, has shown some beneficial effects in rodent models. ${ }^{67}$ Rosiglitazone improved steatosis and transaminase levels, despite significant weight gain. ${ }^{64}$ Even prolonged therapy of rosiglitazone had no substantial improvement in NAS score. ${ }^{68}$ A meta-analysis of four trials did not show improvement in fibrosis with the use of TZD therapy; although, there was a significant improvement in steatosis and inflammation. ${ }^{69}$ Weight gain remains the major concern associated with the use of TZD.6,64,70

PPAR $\beta / \delta$ agonists, are universally present in all cells of the body and are involved in regulating mitochondrial metabolism and fatty acid beta-oxidation. ${ }^{71}$ The data regarding the effectiveness of PPARס agonists for the treatment of NAFLD are limited, precluding formulation of any conclusions. ${ }^{72}$

\section{Dual agonists}

Glitazars are a group of drugs that have PPARa/Y agonism and can improve dyslipidemia and insulin resistance. ${ }^{73}$ Muraglitazar and aleglitazar posed severe safety concerns for cardiovascular events and weight gain and were withdrawn. ${ }^{74,75}$ Saroglitazar, a dual PPARa/y agonist, was recently approved by the Drugs Controller General of India (known as the DCGI) for the treatment of NASH. Saroglitazar has promising results in the treatment of $\mathrm{NASH}$. Elafibranor, a PPARa/ $\delta$ agonist, also had favorable results in preclinical trials. Bezafibrate is also a dual PPARa/ $\delta$ agonist and has some in vitro studies supporting its use in $\mathrm{NASH}$, but there are no clinical studies on its efficacy in NASH. ${ }^{76}$

\section{Saroglitazar}

PPARa agonism is thought to affect fatty acid catabolism/ dyslipidemia, while PPARY has an impact on glycemic con- 


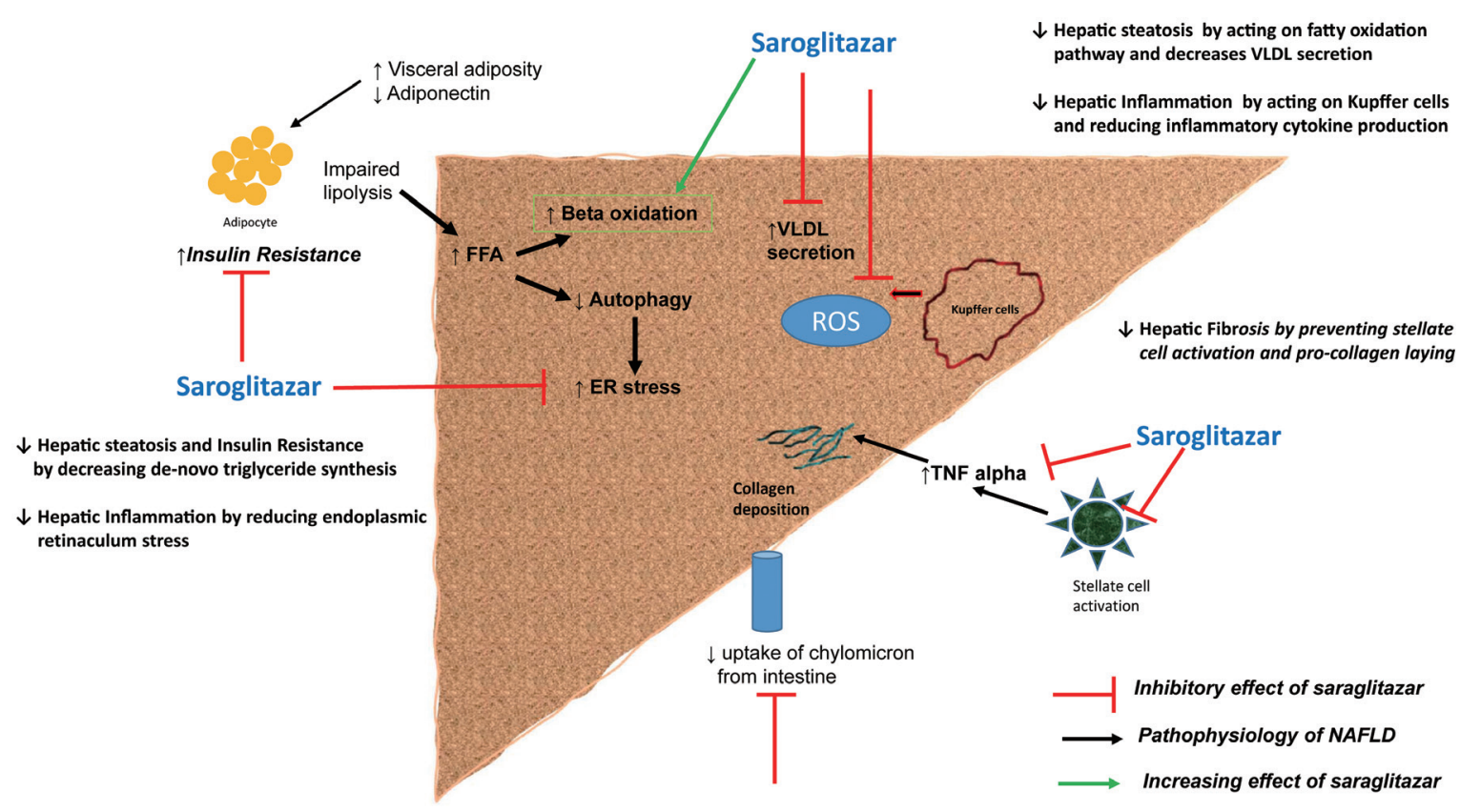

Fig. 3. Mechanism of action of saroglitazar in NASH. The pathophysiology of NASH is depicted in the pathway with black arrows. Saroglitazar increases betaoxidation (green arrows) and decreases lipolysis (red arrows), leading to decrease in free fatty acids. In addition, it reduces ER stress and stellate cell activation (red arrows). This leads to decreased hepatic steatosis and inflammation, reduction in hepatic fibrosis, and improvement in insulin resistance. Abbreviations: ER, endoplasmic reticulum; FFA, free fatty acid IL-6, interleukin-6; ROS, reactive oxygen species; TG, triglyceride; TNF, tumor necrosis factor; VLDL, very low-density lipoprotein.

trol and insulin sensitization. A combination of fenofibrate (PPARa) and rosiglitazone (PPARY) improved diabetic dyslipidemia and glycemic control. 77 Saroglitazar is a dominant PPARa agonist and is effective in improving insulin sensitivity. ${ }^{78,79}$ Saroglitazar in mice has shown to ameliorate NASH through down-regulation of the hepatic lipopolysaccharide/ toll-like receptor-4 pathway and inhibition of adipocyte dysfunction. 80 Saroglitazar prevents weight gain, normalizes liver enzymes, improves insulin resistance, dyslipidemia, and hepatic inflammation in NASH mice. ${ }^{80}$ Saroglitazar also led to a significant change in adipokine levels, resulting in a substantial decrease in serum leptin and TNF-a level. ${ }^{80}$ In NASH models, saroglitazar reduced hepatic steatosis, inflammation, ballooning, and fibrosis. ${ }^{81}$ It also reduced liver enzymes and the expression of inflammatory and fibrosis biomarkers. Saroglitazar led to a significant reduction in the NAS score, better than that achieved with pioglitazone and fenofibrate. ${ }^{81,82}$ The mechanism of action of saroglitazar is shown in Fig. 3. A recent randomized multicenter placebo-controlled trial using different doses of saroglitazar (the EVIDENCE IV trial) was presented as an abstract at the annual meeting of the American Association for the Study of Liver Diseases (AASLD). Saroglitazar at $4 \mathrm{mg}$ improved dyslipidemia, hepatic steatosis, and insulin resistance, when compared to placebo (L010 AASLD 2019). ${ }^{83}$ Another phase 3 multicenter, double-blind, randomized study concluded that saroglitazar at $4 \mathrm{mg}$ for 52 weeks improved NAS score, transaminitis, and lipid profile without fibrosis worsening [Abstract 1427, APASL liver meet 2020 Hepatol Int (2020) 14 (Suppl 1): S326].

\section{Elafibranor}

Elafibranor (GFT505) is a PPARa/ס agonist under evaluation for the treatment of NASH. It has been shown in in vivo studies on Western diet-fed, human apolipoprotein E2 transgenic mice to improve steatosis, inflammation, and fibrosis. ${ }^{84}$ The study also demonstrated that the drug de- creased hepatic lipid accumulation and inhibited pro-inflammatory and profibrotic gene expression. In the initial multicenter, double-blind placebo-controlled randomized trial (the GOLDEN-505 trial), elafibranor at $80 \mathrm{mg}$ and $120 \mathrm{mg}$ were compared against placebo for treatment of NASH for 52 weeks. ${ }^{85}$ In the intention-to-treat (ITT) analysis, no difference was noted in the protocol-defined primary outcome, which was NASH resolution without fibrosis worsening. However, in a post ad hoc modified endpoint, NASH resolution without fibrosis worsening was higher with elafibranor at $120 \mathrm{mg}$ compared to placebo ( $19 \%$ vs. $12 \% ; p=0.045)$. Improvement in NAS score was seen in $20 \%$ of patients with elafibranor at $120 \mathrm{mg}$ compared to only $11 \%$ in the placebo group $(p=0.018) .{ }^{85}$ Elafibranor was associated with a mild reversible rise in serum creatinine but had no adverse effects on cardiac profile or body weight. Recently, the disappointing results of the phase 3 trial on elafibranor (the RESOLVE-IT trial) were announced. In the ITT analysis of 1,070 patients, the response rate (NASH resolution without fibrosis worsening) was $19.2 \%$ for patients who received elafibranor at $120 \mathrm{mg}$ compared to $14.7 \%$ for the placebo arm. Twenty-five percent of patients who received elafibranor at $120 \mathrm{mg}$ achieved fibrosis improvement compared to $22.4 \%$ in the placebo arm. There was also no significant improvement in other biochemical parameters.

Lanifibranor (IVA337) is a pan-PPAR agonist, which has been shown to improve all the histological factors of NASH, including fibrosis, in experimental mouse models. ${ }^{86} \mathrm{~A}$ phase 2 randomized placebo-controlled trial is under evaluation for assessing the safety and efficacy of lanifibranor in patients with T2DM and NAFLD (NCT03459079).

\section{Arachidyl-amido cholanoic acid (aramchol)}

Aramchol is an inhibitor of stearoyl-Co-A desaturase 1 (known as SCD1), which is an enzyme located in the endoplasmic reticulum and catalyzes the rate-limiting step of monoun- 
saturated fatty acid formation and prevents de novo lipogenesis. ${ }^{87}$ Initial studies on the methionine and choline-deficient diet model of NASH showed down-regulation of SCD1, along with increasing flux through the trans-sulphuration pathway, thereby maintaining cellular redox homeostasis. ${ }^{88}$

A double-blind, multicenter placebo-controlled trial on biopsy-proven NASH comparing aramchol at $100 \mathrm{mg}$ or 300 $\mathrm{mg}$ against placebo for 3 months concluded that there was significant reduction in hepatic fat content with aramchol at $300 \mathrm{mg} .{ }^{89}$ An open-labeled safety study was conducted on 16 healthy volunteers (Abstract \#2326 Liver meeting AASLD 2019). Twice-daily dosing with aramchol at $300 \mathrm{mg}$ resulted in significantly higher exposures than once-daily dosing of aramchol at $600 \mathrm{mg}$. Both dosing regimens were safe and tolerable, without any adverse effects. Currently, a double-blind, placebo-controlled randomized phase 3 study with aramchol at $300 \mathrm{mg}$ in subjects with NASH and F2-3 who are overweight (or obese) and have prediabetes or adequately controlled T2DM (the ARMOR study) is underway (NCT04104321).

\section{Cenicriviroc (CVC)}

CVC is a dual human C-C motif chemokine receptor type 2 and 5 (CCR2/CCR5 chemokine) antagonist. CVC-mediated antagonism of CCR2 reduces the recruitment, migration, and infiltration of pro-inflammatory monocytes and macrophages at the site of liver injury. ${ }^{90,91}$ CCR5 antagonism by CVC is expected to additionally impair the migration, activation, and proliferation of collagen-producing activated hepatic stellate cells/myofibroblasts. ${ }^{91,92}$ The CENTAUR phase $2 b$ study included patients with NAS score $\geq 4$ and NASHCRN fibrosis stage 1-3. The study concluded that CVC improved fibrosis in patients with $\mathrm{NASH}$, and most of these improvements occur at year 1 and are maintained until the end of the $2^{\text {nd }}$ year. ${ }^{93,94}$ Phase 3 (the AURORA study) trial is designed to strengthen the findings of this drug further. ${ }^{95}$ In this multicenter, randomized, double-blind, placebocontrolled study (NCT030328740) of approximately 2,000 adults with histological evidence of NASH and F2-3 fibrosis will be randomized in 2:1 ratio to oral CVC $150 \mathrm{mg}$ or placebo once daily. The primary efficacy endpoint includes the proportion of subjects with $\geq 1$-stage improvement in liver fibrosis and no worsening of steatohepatitis at 1 year. The results are expected by September 2020.

\section{Glucagon-like peptide-1 (GLP-1) inhibitors}

Liraglutide is a human incretin (GLP-1) agonist. Liraglutide alleviated the features of metabolic syndrome in rats fed with a high-fat diet. ${ }^{6}$ Liraglutide improved glucose tolerance, reduced weight gain, triglyceride levels, and liver fat accumulation. 96 The initial randomized study compared liraglutide at $1.8 \mathrm{mg}$ against placebo for 12 weeks. Liraglutide reduced the body mass index, improved hepatic and adipose tissue insulin sensitivity, and also improved glycemic control, all of which form the major component in NASH pathogenesis. ${ }^{97} \mathrm{~A}$ subsequent multicenter randomized phase 2 placebo-controlled trial (the LEAN trial) found that liraglutide is safe, well-tolerated, and leads to histological resolution of NASH (39\% vs. $9 \%$ in placebo; $p=0.019) .98$ The progression of fibrosis was also more significant in the placebo arm (36\% vs. $9 \% ; p=0.04)$. Common side effects with liraglutide were gastrointestinal in $81 \%$ of patients, and the most common were nausea and diarrhea. ${ }^{98}$ There are conflicting reports of increased incidence of pancreatic cancer and acute pancreatitis with this incretin analogue. ${ }^{99,100}$ However, further studies are ongoing comparing liraglutide and bariatric surgery in obese Asian NASH patients, and results are awaited (NCT02654665).

Semaglutide is another GLP-1 agonist discovered in 2012 and approved for the treatment of T2DM since 2017. It is currently being investigated for NASH. A double-blind placebo-controlled trial for 52 weeks with semaglutide and lifestyle modification has shown significant weight loss compared to liraglutide and placebo. ${ }^{101}$ The cardiovascular outcomes of 104 subjects with dose of semaglutide at 0.5 or 1.0 mg/week in T2DM (the SUSTAIN-6 trial; NCT01720446) and a 52-week weight management trial with a dose of semaglutide at $0.05-0.4 \mathrm{mg} /$ day (NCT02453711) were analyzed. Semaglutide had cardioprotective effects in T2DM patients. Among subjects treated with semaglutide (especially at $0.4 \mathrm{mg} /$ day), the proportion of patients with metabolic syndrome approximately halved during the trial compared with the baseline. 102 Semaglutide also reduced inflammatory markers and aminotransferases. ${ }^{102}$ The investigation of semaglutide at $0.1,0.2$ and $0.4 \mathrm{mg} /$ day for $\mathrm{NASH}$ resolution without fibrosis worsening after 72 weeks of therapy has recently been completed, and the results are expected (NCT02970942).

\section{Galectin-3 inhibitors (GT-MD-02)}

Galectins are conserved proteins with the ability to bind $\beta$ galactosides through carbohydrate-recognition domains. ${ }^{103}$ Galectin-3 contains a C-terminal carbohydrate-recognition domain linked to an $\mathrm{N}$-terminal protein-binding domain and is a unique chimeric galectin. ${ }^{103}$ In the cytoplasm, galectin-3 is vital for cell survival due to its interaction with specific survival-associated proteins. In the nucleus, galectin-3 promotes pre-mRNA splicing and regulates gene transcription, whereas extracellular galectin-3 modulates cell-cell interactions. Thus, it is involved in cell differentiation, inflammation, fibrogenesis, and the host defense. 104

Galactoarabino-rhamnogalacturonan, belapectin (GRMD-02), binds mostly to galectin-3 receptors and has been hypothesized to manipulate the upstream events in the pathogenesis of NASH, which leads to substrate overload. ${ }^{105}$ The sequential dose-ranging, placebo-controlled, doubleblinded safety study in biopsy-proven NASH patients with advanced fibrosis (Brunt stage 3 ) revealed no difference in adverse effects when GR-MD-02 single or three weekly repeated doses of 2,4 or $8 \mathrm{mg} / \mathrm{kg}$ was used. ${ }^{106}$ Galectin-3 ablation protects from diet-induced NASH by decreasing hepatic advanced lipoxidation end products' accumulation, with attenuation of inflammation, hepatocyte injury, and fibrosis. ${ }^{107} \mathrm{~A}$ multicenter phase $2 \mathrm{~b}$, randomized trial has enrolled patients with NASH, cirrhosis, and portal hypertension to randomly receive biweekly infusions of belapectin at a dose of $2 \mathrm{mg} / \mathrm{kg}$ or $8 \mathrm{mg} / \mathrm{kg}$ or placebo for 52 weeks. Although belapectin was safe, it was not associated with a significant reduction in hepatic venous pressure gradient (HVPG) or fibrosis compared to placebo. In the subgroup analysis of patients without esophageal varices, $2 \mathrm{mg} / \mathrm{kg}$ belapectin did reduce HVPG and development of varices. ${ }^{108}$

\section{Emricasan}

Emricasan is a pan-caspase inhibitor that acts on the final apoptotic pathway involved in the pathogenesis of NASH. In a murine model of $\mathrm{NASH}$, hepatocyte apoptosis was attenuated by emricasan, which led to an improvement in fibrosis, bringing forth the use of emricasan as an antifibrotic agent in NASH. ${ }^{109}$ A subsequent multicenter study involving cirrhotic patients (etiology: alcohol, hepatitis $C$ virus, and $\mathrm{NASH}$ ) demonstrated a significant reduction in model for 
end-stage liver disease (MELD score), Child-Pugh scores, international normalized ratio, and total bilirubin in patients with MELD scores $\geq 15$ following emricasan $25 \mathrm{mg} .{ }^{110} \mathrm{~A}$ multicenter, double-blind, randomized trial recruited 263 patients with NASH-related cirrhosis and baseline HVPG of $\geq 12 \mathrm{mmHg}$. These patients were treated with twice-daily with oral emricasan at $5 \mathrm{mg}, 25 \mathrm{mg}$ or $50 \mathrm{mg}$, or placebo in a $1: 1: 1: 1$ ratio for up to 48 weeks. The primary endpoint was change in HVPG $(\triangle H V P G)$ at week 24 . Secondary endpoints were changes in biomarkers (aminotransferases, caspases, cytokeratins) and development of liver-related outcomes. Although emricasan was safe, there was no reduction in HVPG or biomarkers. ${ }^{111}$ Similarly, another randomized placebo-controlled trial with NASH patients with F1-F3 fibrosis with emricasan ( $5 \mathrm{mg}$ or $50 \mathrm{mg}$ ) for 72 weeks did not improve liver histology in patients with NASH fibrosis and showed a trend towards worsening of fibrosis and ballooning. ${ }^{112}$ This drug is unlikely to hold promise.

\section{Selonsertib}

Selonsertib is an inhibitor of apoptosis signal-regulating kinase 1 (ASK1), with potential anti-inflammatory and antifibrotic properties. A preliminary study of NASH was conducted with F2-3 fibrosis patients treated with selonsertib at $6 \mathrm{mg}$ or $18 \mathrm{mg}$ orally alone or in combination with simtuzumab (125 mg subcutaneously weekly) or simtuzumab alone for 24 weeks. The study demonstrated a decrease in hepatic collagen with the use of selonsertib. ${ }^{113}$ A follow-up study that used magnetic resonance imaging (MRI)-based evaluation of fibrosis assessment in patients receiving selonsertib showed a positive trend warranting further investigations. ${ }^{114}$ Two subsequent randomized, double-blind, placebo-controlled, phase 3 trials of selonsertib in patients with NASH and bridging fibrosis F3 (STELLAR-3 trial) or compensated cirrhosis (STELLAR-4 trial) were conducted, wherein patients were randomized 2:2:1 to receive selonsertib at $18 \mathrm{mg}$, selonsertib at $6 \mathrm{mg}$, or placebo once daily for 48 weeks. ${ }^{115}$ Neither of these trials met the primary endpoint, and no improvement in fibrosis was noted.

\section{Tipelukast}

$\mathrm{MN}-001$ is an antifibrotic and anti-inflammatory molecule that acts by antagonizing leukotriene receptors (referred to here as LT), phosphodiesterases, and 5-lipoxygenase (referred to here as 5-LO). ${ }^{116}$ The inhibitory effect of tipelukast on the 5-LO/LT pathway may contribute to its antifibrotic effects. In an interim report of nine NASH/NAFLD patients with hypertriglyceridemia who completed tipelukast (MN001) at $250 \mathrm{mg}$ qd for the first 4 weeks, tipelukast significantly reduced triglycerides. ${ }^{117}$ The complete results are awaited (NCT02681055).

\section{Volixibat}

Volixibat (SHP626) is a potent inhibitor of the apical sodiumdependent bile acid transporter (ASBT). In the initial phase 1 study, the absorption of the drug was found to be very low after oral ingestion. ${ }^{118}$ The drug was reviewed based on the hypothesis that ASBT inhibition in the terminal ileum would facilitate the removal of free cholesterol in the liver by reducing the recirculation of bile acids to the liver and promoting new bile acid synthesis. A randomized controlled trial comparing volixibat at $0.5 \mathrm{mg}, 1 \mathrm{mg}, 5 \mathrm{mg}$, or $10 \mathrm{mg}$ against placebo for 28 days in healthy volunteers and T2DM patients showed increased fecal excretion of bile acids with an elevation of serum $\mathrm{C} 4$ levels in both groups. ${ }^{119} \mathrm{~A}$ recent randomized, double-blind trial recruited steatosis and noncirrhotic NASH patients treated with volixibat at $5 \mathrm{mg}, 10$ $\mathrm{mg}$, or $20 \mathrm{mg}$ or placebo once daily for 48 weeks. ${ }^{120}$ The study failed to reach the primary endpoint, which was defined as a $\geq 5 \%$ reduction in MRI-proton density fat fraction (PDFF) and $\geq 20 \%$ reduction in serum ALT level at interim analysis at 24 weeks, and the study was terminated.

\section{NS-0200}

The $5^{\prime}$ adenosine monophosphate-activated protein kinase (AMPK)/Sirtuin 1 (Sirt1) pathway is a crucial regulator of mitochondrial biogenesis, energy, and lipid metabolism. ${ }^{121}$ Activation of this pathway may reverse or at least prevent excess hepatic lipid accumulation and inflammation. Lleucine is an activator of the SIRT1/AMPK pathway, serving as a partial mimetic of calorie restriction in preclinical models, and thereby modulates lipid and energy metabolism and increases insulin sensitivity. ${ }^{122}$ The combination of leucine with low-dose metformin reversed hepatic steatosis in preclinical studies in murine models of T2DM and NASH. Adding low-dose sildenafil enhances this effect by stimulating endothelial nitric oxide synthase activity, leading to exacerbated stimulation of Sirt1 and thereby attenuating inflammation and fibrosis. ${ }^{123,124}$ NS-0200 is a leucine-metformin-sildenafil fixed-dose combination that may reduce hepatic steatosis and improve metabolic parameters. The study revealed that high-dose NS-0200 relatively reduced hepatic fat by $15.7 \%$ from baseline in the high ALT group $(p<0.005)$, while no such benefit was seen at lower doses. ${ }^{125}$ Further studies are underway for this combination. The effect of high- and low-dose NS-0200 on the fat content (MRI-PDFF) is being assessed in a randomized, 16-week, placebo-controlled, double-blind study in NAFLD patients (NCT02546609).

\section{Conclusions}

Although many drugs fared well in animal models, the clinical utility of these drugs is limited in humans. The animal models are usually controlled for various confounders, and hence they may be an accurate representation of disease. However, no animal models can completely replicate the heterogeneous nature and physiological condition of human beings. The response to an injury is different in each individual. Hence, very few drugs have managed to progress into use in clinical practice. Despite many drugs being under evaluation, the only established treatment of NASH at this point is weight loss. Medications are currently used with no FDA approval as an adjunct to lifestyle changes in patients with biopsy-proven NASH. The two drugs ahead in the pipeline are OCA, which is awaiting FDA approval and saroglitazar, which has been approved only in India for use in $\mathrm{NASH}$, although long-term data on fibrosis improvement are still awaited.

\section{Funding}

None to declare.

\section{Conflict of interest}

The authors have no conflict of interests related to this publication. 


\section{Author contributions}

Conceptualization and study design (MS, AVK), data acquisition (MS, MP), initial drafting of the manuscript (MS, AVK, $M P)$, figure generation (MS, PK), critical assessment of the manuscript, and provision of intellectual input (DNR, PNR), article guarantor (AVK). All authors approved the final draft.

\section{References}

[1] Issa $D$, Patel $V$, Sanyal AJ. Future therapy for non-alcoholic fatty liver disease. Liver Int 2018;38(Suppl 1):56-63. doi:10.1111/liv.13676.

[2] Li J, Zou B, Yeo YH, Feng Y, Xie X, Lee DH, et al. Prevalence, incidence, and outcome of non-alcoholic fatty liver disease in Asia, 1999-2019: a systematic review and meta-analysis. Lancet Gastroenterol Hepatol 2019;4:389398. doi:10.1016/S2468-1253(19)30039-1.

[3] Ludwig J, Viggiano TR, McGill DB, Oh BJ. Nonalcoholic steatohepatitis: Mayo Clinic experiences with a hitherto unnamed disease. Mayo Clin Proc 1980;55:434-438.

[4] Eslam M, Sanyal AJ, George J. MAFLD: A consensus-driven proposed nomenclature for metabolic associated fatty liver disease. Gastroenterology 2020;158:1999-2014.e1. doi:10.1053/j.gastro.2019.11.312.

[5] Zhu FS, Liu S, Chen XM, Huang ZG, Zhang DW. Effects of n-3 polyunsaturated fatty acids from seal oils on nonalcoholic fatty liver disease as sociated with hyperlipidemia. World J Gastroenterol 2008;14:6395-6400. doi:10.3748/wjg.14.6395

[6] Sanyal AJ, Chalasani N, Kowdley KV, McCullough A, Diehl AM, Bass NM, et al. Pioglitazone, vitamin $\mathrm{E}$, or placebo for nonalcoholic steatohepatitis. N Engl ] Med 2010;362:1675-1685. doi:10.1056/NEJMoa0907929.

[7] Lindor KD, Kowdley KV, Heathcote EJ, Harrison ME, Jorgensen R, Angulo P, et al. Ursodeoxycholic acid for treatment of nonalcoholic steatohepatitis: results of a randomized trial. Hepatology 2004;39:770-778. doi:10.1002/ hep. 20092

[8] Lavine JE, Schwimmer JB, Van Natta ML, Molleston JP, Murray KF, Rosenthal $P$, et al. Effect of vitamin $E$ or metformin for treatment of nonalcoholic fatty liver disease in children and adolescents: the TONIC randomized controlled trial. JAMA 2011;305:1659-1668. doi:10.1001/jama.2011.520.

[9] Argo CK, Patrie JT, Lackner C, Henry TD, de Lange EE, Weltman AL, et al. Effects of $n-3$ fish oil on metabolic and histological parameters in NASH: a double-blind, randomized, placebo-controlled trial. J Hepato 2015;62:190-197. doi:10.1016/j.jhep.2014.08.036.

[10] Scorletti E, Bhatia L, McCormick KG, Clough GF, Nash K, Hodson L, et al. Effects of purified eicosapentaenoic and docosahexaenoic acids in nonalcoholic fatty liver disease: results from the Welcome* study. Hepatology 2014;60:1211-1221. doi:10.1002/hep.27289.

[11] Younossi ZM, Ratziu V, Loomba R, Rinella M, Anstee QM, Goodman Z, et al. Obeticholic acid for the treatment of non-alcoholic steatohepatitis: interim analysis from a multicentre, randomised, placebo-controlled phase 3 trial. Lancet 2019;394:2184-2196. doi:10.1016/S0140-6736(19)33041-7.

[12] Friedman LM, Furberg CD, DeMets D, Reboussin DM, Granger CB. Fundamentals of clinical trials. Springer; 2010.

[13] Rinella ME, Tacke F, Sanyal AJ, Anstee QM. Report on the AASLD/EASL joint workshop on clinical trial endpoints in NAFLD. Hepatology 2019;70:14241436. doi:10.1002/hep.30782.

[14] Hannah WN Jr, Torres DM, Harrison SA. Nonalcoholic steatohepatitis and endpoints in clinical trials. Gastroenterol Hepatol (N Y) 2016;12:756-763.

[15] Sanyal AJ, Brunt EM, Kleiner DE, Kowdley KV, Chalasani N, Lavine JE, et al. Endpoints and clinical trial design for nonalcoholic steatohepatitis. Hepatology 2011;54:344-353. doi:10.1002/hep.24376.

[16] Kleiner DE, Brunt EM, Van Natta M, Behling C, Contos MJ, Cummings OW, et al. Design and validation of a histological scoring system for nonalcoholic fatty liver disease. Hepatology 2005;41:1313-1321. doi:10.1002/ hep.20701.

[17] Bedossa P, Poitou C, Veyrie N, Bouillot JL, Basdevant A, Paradis V, et al. Histopathological algorithm and scoring system for evaluation of liver lesions in morbidly obese patients. Hepatology 2012;56:1751-1759. doi:10.1002/ hep. 25889.

[18] Lonardo A, Ballestri S, Marchesini G, Angulo P, Loria P. Nonalcoholic fatty liver disease: a precursor of the metabolic syndrome. Dig Liver Dis ty liver disease: a precursor of the metabolic sy

[19] Targher G, Byrne CD. A perspective on metabolic syndrome and nonalcoholic fatty liver disease. Metab Syndr Relat Disord 2015;13:235-238. doi:10.1089/met.2015.1502.

[20] Anstee QM, Targher G, Day CP. Progression of NAFLD to diabetes mellitus, cardiovascular disease or cirrhosis. Nat Rev Gastroenterol Hepato 2013;10:330-344. doi:10.1038/nrgastro.2013.41.

[21] Johnston MP, Patel J, Byrne CD. Multi-drug approaches to NASH: what's in the development pipeline? Expert Opin Investig Drugs 2020;29:143-150. doi: 10.1080/13543784.2020.1668926.

[22] Mantovani A, Scorletti E, Mosca A, Alisi A, Byrne CD, Targher G. Complications, morbidity and mortality of nonalcoholic fatty liver disease. Metabolism 2020;111S:154170. doi:10.1016/j.metabol.2020.154170.

[23] Sharma M, Mitnala S, Vishnubhotla RK, Mukherjee R, Reddy DN, Rao PN. The riddle of nonalcoholic fatty liver disease: progression from nonalcoholic fatty liver to nonalcoholic steatohepatitis. J Clin Exp Hepatol 2015;5:147158. doi:10.1016/j.jceh.2015.02.002.
[24] Chalasani N, Younossi Z, Lavine JE, Charlton M, Cusi K, Rinella M, et al. The diagnosis and management of nonalcoholic fatty liver disease: Practice guidance from the American Association for the Study of Liver Diseases. Hepatology 2018;67:328-357. doi:10.1002/hep.29367.

[25] Leoni S, Tovoli F, Napoli L, Serio I, Ferri S, Bolondi L. Current guidelines for the management of non-alcoholic fatty liver disease: A systematic review with comparative analysis. World J Gastroenterol 2018;24:3361-3373. doi:10.3748/wjg.v24.i30.3361.

[26] Musso G, Cassader M, Rosina F, Gambino R. Impact of current treatments on liver disease, glucose metabolism and cardiovascular risk in non-alcoholic fatty liver disease (NAFLD): a systematic review and meta-analysis of randomised trials. Diabetologia 2012;55:885-904. doi:10.1007/s00125011-2446-4

[27] Vilar-Gomez E, Martinez-Perez Y, Calzadilla-Bertot L, Torres-Gonzalez A, Gra-Oramas B, Gonzalez-Fabian L, et al. Weight loss through lifestyle modification significantly reduces features of nonalcoholic steatohepatitis. Gastroenterology 2015;149:367-378.e5. doi:10.1053/j.gastro.2015.04.005.

[28] Saint-Maurice PF, Troiano RP, Bassett DR Jr, Graubard BI, Carlson SA, Shiroma EJ, et al. Association of daily step count and step intensity with mortality among US adults. JAMA 2020;323:1151-1160. doi:10.1001/ jama.2020.1382

[29] Romero-Gómez M, Zelber-Sagi S, Trenell M. Treatment of NAFLD with diet, physical activity and exercise. J Hepatol 2017;67:829-846. doi:10.1016/j. jhep.2017.05.016.

[30] Ryan MC, Itsiopoulos C, Thodis T, Ward G, Trost N, Hofferberth S, et al. The Mediterranean diet improves hepatic steatosis and insulin sensitivity in individuals with non-alcoholic fatty liver disease. J Hepatol 2013;59:138143. doi:10.1016/j.jhep.2013.02.012.

[31] EASL-EASD-EASO Clinical Practice Guidelines for the management of non-alcoholic fatty liver disease. Diabetologia 2016;59:1121-1140. doi:10.1007/ s00125-016-3902-y.

[32] Miller ER 3rd, Pastor-Barriuso R, Dalal D, Riemersma RA, Appel LJ, Guallar E. Meta-analysis: high-dosage vitamin $\mathrm{E}$ supplementation may increase all-cause mortality. Ann Intern Med 2005;142:37-46. doi:10.7326/00034819-142-1-200501040-00110.

[33] Abner EL, Schmitt FA, Mendiondo MS, Marcum JL, Kryscio RJ. Vitamin E and all-cause mortality: a meta-analysis. Curr Aging Sci 2011;4:158-170. doi: $10.2174 / 1874609811104020158$

[34] Klein EA, Thompson IM Jr, Tangen CM, Crowley JJ, Lucia MS, Goodman $\mathrm{PJ}$, et al. Vitamin $\mathrm{E}$ and the risk of prostate cancer: the Selenium and Vitamin E Cancer Prevention Trial (SELECT). JAMA 2011;306:1549-1556. doi:10.1001/jama.2011.1437.

[35] Ekstedt M, Hagström H, Nasr P, Fredrikson M, Stål P, Kechagias S, et al. Fibrosis stage is the strongest predictor for disease-specific mortality in NAFLD after up to 33 years of follow-up. Hepatology 2015;61:1547-1554. doi:10.1002/hep. 27368

[36] Beraza N, Ofner-Ziegenfuss L, Ehedego $H$, Boekschoten M, Bischoff SC, Mueller M, et al. Nor-ursodeoxycholic acid reverses hepatocyte-specific nemo-dependent steatohepatitis. Gut 2011;60:387-396. doi:10.1136/gut. 2010.223834

[37] Traussnigg S, Schattenberg JM, Demir M, Wiegand J, Geier A, Teuber G, et al. Norursodeoxycholic acid versus placebo in the treatment of non-alcoholic fatty liver disease: a double-blind, randomised, placebo-controlled, phase 2 dose-finding trial. Lancet Gastroenterol Hepatol 2019;4:781-793. doi:10.1016/S2468-1253(19)30184-0.

[38] Yang J, Fernández-Galilea M, Martínez-Fernández L, González-Muniesa $P$, Pérez-Chávez A, Martínez JA, et al. Oxidative stress and non-alcoholic fatty liver disease: Effects of omega-3 fatty acid supplementation. Nutrients 2019;11:872. doi:10.3390/nu11040872.

[39] Sanyal AJ, Abdelmalek MF, Suzuki A, Cummings OW, Chojkier M. No significant effects of ethyl-eicosapentanoic acid on histologic features of nonalcoholic steatohepatitis in a phase 2 trial. Gastroenterology 2014;147:377384.e1. doi:10.1053/j.gastro.2014.04.046.

[40] Parker HM, Johnson NA, Burdon CA, Cohn JS, O'Connor HT, George J. Omega-3 supplementation and non-alcoholic fatty liver disease: a systematic review and meta-analysis. J Hepatol 2012;56:944-951. doi:10.1016/j. jhep.2011.08.018.

[41] Bugianesi E, Gentilcore E, Manini R, Natale S, Vanni E, Villanova N, et al. A randomized controlled trial of metformin versus vitamin $E$ or prescriptive diet in nonalcoholic fatty liver disease. Am J Gastroenterol 2005;100:1082-1090. doi:10.1111/j.1572-0241.2005.41583.x.

[42] Li Y, Liu L, Wang B, Wang J, Chen D. Metformin in non-alcoholic fatty liver disease: A systematic review and meta-analysis. Biomed Rep 2013;1:5764. doi:10.3892/br.2012.18.

[43] Sawangjit R, Chongmelaxme B, Phisalprapa P, Saokaew S, Thakkinstian $\mathrm{A}$, Kowdley $\mathrm{KV}$, et al. Comparative efficacy of interventions on nonalcoholic fatty liver disease (NAFLD): A PRISMA-compliant systematic review and network meta-analysis. Medicine (Baltimore) 2016;95:e4529. doi:10.1097/MD.0000000000004529.

[44] Koppe SW, Sahai A, Malladi P, Whitington PF, Green RM. Pentoxifylline attenuates steatohepatitis induced by the methionine choline deficient diet. J Hepatol 2004;41:592-598. doi:10.1016/j.jhep.2004.06.030.

[45] Zein CO, Yerian LM, Gogate P, Lopez R, Kirwan JP, Feldstein AE, et al. Pentoxifylline improves nonalcoholic steatohepatitis: a randomized placebocontrolled trial. Hepatology 2011;54:1610-1619. doi:10.1002/hep.24544.

[46] Raetsch C, Jia JD, Boigk G, Bauer M, Hahn EG, Riecken EO, et al. Pentoxifylline downregulates profibrogenic cytokines and procollagen I expression in rat secondary biliary fibrosis. Gut 2002;50:241-247. doi:10.1136/ gut.50.2.241.

[47] Van Wagner LB, Koppe SW, Brunt EM, Gottstein J, Gardikiotes K, Green $\mathrm{RM}$, et al. Pentoxifylline for the treatment of non-alcoholic steatohepatitis: 
a randomized controlled trial. Ann Hepatol 2011;10:277-286.

[48] Younossi ZM, Tampi R, Priyadarshini M, Nader F Younossi IM, Racila A. Burden of illness and economic model for patients with nonalcoholic steatohepatitis in the United States. Hepatology 2019;69:564-572. doi:10.1002/ hep.30254.

[49] Hoofnagle JH. FXR agonists as therapy for liver disease. Hepatology 2020;72:1-3. doi:10.1002/hep.31265.

[50] Lazarević S, Đanić M, Goločorbin-Kon S, Al-Salami H, Mikov M. Semisynthetic bile acids: a new therapeutic option for metabolic syndrome. Pharmacol Res 2019;146:104333. doi:10.1016/j.phrs.2019.104333.

[51] Pellicciari R, Fiorucci S, Camaioni E, Clerici C, Costantino G, Maloney PR, et al. 6alpha-ethyl-chenodeoxycholic acid (6-ECDCA), a potent and selective FXR agonist endowed with anticholestatic activity. J Med Chem 2002;45:3569-3572. doi:10.1021/jm025529g.

[52] Neuschwander-Tetri BA, Loomba R, Sanyal AJ, Lavine JE, Van Natta ML, Abdelmalek MF, et al. Farnesoid X nuclear receptor ligand obeticholic acid for non-cirrhotic, non-alcoholic steatohepatitis (FLINT): a multicentre, randomised, placebo-controlled trial. Lancet 2015;385:956-965. doi:10.1016/S0140-6736(14)61933-4.

[53] Ratziu V, Sanyal AJ, Loomba R, Rinella M, Harrison S, Anstee QM, et al. REGENERATE: Design of a pivotal, randomised, phase 3 study evaluating the safety and efficacy of obeticholic acid in patients with fibrosis due to nonalcoholic steatohepatitis. Contemp Clin Trials 2019;84:105803. doi:10.1016/ j.cct.2019.06.017.

[54] Gawrieh S, Guo X, Tan J, Lauzon M, Taylor KD, Loomba R, et al. A pilot genome-wide analysis study identifies loci associated with response to obeticholic acid in patients with NASH. Hepatol Commun 2019;3:1571-1584. doi:10.1002/hep4.1439.

[55] Chapman RW, Lynch KD. Obeticholic acid-a new therapy in PBC and NASH. Br Med Bull 2020;133:95-104. doi:10.1093/bmb/ldaa006.

[56] Posters (Abstracts 289-2348). Hepatology 2019;70:188-1382. doi:10.1002/hep.30941.

[57] Siddiqui MS, Van Natta ML, Connelly MA, Vuppalanchi R, NeuschwanderTetri BA, Tonascia J, et al. Impact of obeticholic acid on the lipoprotein profile in patients with non-alcoholic steatohepatitis. J Hepatol 2020;72:2533. doi:10.1016/j.jhep.2019.10.006

[58] Feng C. Clarification of obeticholic acid dosing: Response to "Occurrence of jaundice following simultaneous ursodeoxycholic acid cessation and obeticholic acid initiation" by Quigley et al. Dig Dis Sci 2018;63:1980-1981. doi:10.1007/s10620-018-5083-7.

[59] Boeckmans J, Natale A, Rombaut M, Buyl K, Rogiers V, De Kock J, et al. Anti-NASH drug development hitches a lift on PPAR agonism. Cells 2019;9:37. doi:10.3390/cells9010037.

[60] Grygiel-Górniak B. Peroxisome proliferator-activated receptors and their ligands: nutritional and clinical implications-a review. Nutr J 2014;13:17. doi:10.1186/1475-2891-13-17.

[61] Laurin J, Lindor KD, Crippin JS, Gossard A, Gores GJ, Ludwig J, et al. Ursodeoxycholic acid or clofibrate in the treatment of non-alcohol-induced steatohepatitis: a pilot study. Hepatology 1996;23:1464-1467. doi:10.1002/ hep. 510230624

[62] Fernández-Miranda C, Pérez-Carreras M, Colina F, López-Alonso G, Vargas C, Solís-Herruzo JA. A pilot trial of fenofibrate for the treatment of non-alcoholic fatty liver disease. Dig Liver Dis 2008;40:200-205. doi:10.1016/j. dld.2007.10.002.

[63] Yu S, Matsusue K, Kashireddy $P$, Cao WQ, Yeldandi V, Yeldandi AV, et al. Adipocyte-specific gene expression and adipogenic steatosis in the mouse liver due to peroxisome proliferator-activated receptor gamma1 (PPARgamma1) overexpression. J Biol Chem 2003;278:498-505. doi:10.1074/ jbc.M210062200.

[64] Ratziu V, Giral P, Jacqueminet S, Charlotte F, Hartemann-Heurtier A, Serfaty $L$, et al. Rosiglitazone for nonalcoholic steatohepatitis: one-year results of the randomized placebo-controlled Fatty Liver Improvement with Rosiglitazone Therapy (FLIRT) Trial. Gastroenterology 2008;135:100-110. doi:10.1053/j.gastro.2008.03.078

[65] Hsiao PJ, Hsieh TJ, Kuo KK, Hung WW, Tsai KB, Yang CH, et al. Pioglitazone retrieves hepatic antioxidant DNA repair in a mice model of high fat diet. BMC Mol Biol 2008;9:82. doi:10.1186/1471-2199-9-82

[66] Cheng J, Joyce A, Yates K, Aouizerat B, Sanyal AJ. Metabolomic profiling to identify predictors of response to vitamin $\mathrm{E}$ for non-alcoholic steatohepatitis (NASH). PLoS One 2012; 7:e44106. doi:10.1371/journal.pone.0044106.

[67] Nan YM, Fu N, Wu WJ, Liang BL, Wang RQ, Zhao SX, et al. Rosiglitazone prevents nutritional fibrosis and steatohepatitis in mice. Scand J Gastroenterol 2009;44:358-365. doi:10.1080/00365520802530861.

[68] Ratziu V, Charlotte F, Bernhardt C, Giral P, Halbron M, Lenaour G, et al. Long-term efficacy of rosiglitazone in nonalcoholic steatohepatitis: results of the fatty liver improvement by rosiglitazone therapy (FLIRT 2) extension trial. Hepatology 2010;51:445-453. doi:10.1002/hep.23270.

[69] Boettcher E, Csako G, Pucino F, Wesley R, Loomba R. Meta-analysis: pioglitazone improves liver histology and fibrosis in patients with non-alcoholic steatohepatitis. Aliment Pharmacol Ther 2012;35:66-75. doi:10.1111/ j.1365-2036.2011.04912.x.

[70] Cusi K, Orsak B, Bril F, Lomonaco R, Hecht J, Ortiz-Lopez C, et al. Longterm pioglitazone treatment for patients with nonalcoholic steatohepatitis and prediabetes or type 2 diabetes mellitus: A randomized trial. Ann Intern and prediabetes or type 2 diabetes mellitus: A randor

[71] Tanaka T, Yamamoto J, Iwasaki S, Asaba H, Hamura H, Ikeda $Y$, et al. Activation of peroxisome proliferator-activated receptor delta induces fatty acid beta-oxidation in skeletal muscle and attenuates metabolic syndrome. Proc Natl Acad Sci U S A 2003;100:15924-15929. doi:10.1073/ pnas.0306981100.

[72] Mackenzie LS, Lione L. Harnessing the benefits of PPAR $/ \delta$ agonists. Life
Sci 2013;93:963-967. doi:10.1016/j.Ifs.2013.10.022

[73] Brand CL, Sturis J, Gotfredsen CF, Fleckner J, Fledelius C, Hansen BF, et al. Dual PPARalpha /gamma activation provides enhanced improvement of insulin sensitivity and glycemic control in ZDF rats. Am J Physiol Endocrinol Metab 2003;284:E841-E854. doi:10.1152/ajpendo.00348.2002.

[74] Nissen SE, Wolski K, Topol EJ. Effect of muraglitazar on death and major adverse cardiovascular events in patients with type 2 diabetes mellitus. JAMA 2005;294:2581-2586. doi:10.1001/jama.294.20.joc50147.

[75] Henry RR, Lincoff AM, Mudaliar S, Rabbia M, Chognot C, Herz M. Effect of the dual peroxisome proliferator-activated receptor-alpha/gamma agonist aleglitazar on risk of cardiovascular disease in patients with type 2 diabetes (SYNCHRONY): a phase II, randomised, dose-ranging study. Lancet 2009;374:126-135. doi:10.1016/S0140-6736(09)60870-9.

[76] Nakano S, Nagasawa T, Ijiro T, Inada Y, Tamura T, Maruyama K, et al. Bezafibrate prevents hepatic stellate cell activation and fibrogenesis in a murine steatohepatitis model, and suppresses fibrogenic response induced by transforming growth factor-beta 1 in a cultured stellate cell line. Hepatol Res 2008;38:1026-1039. doi:10.1111/j.1872-034X.2008.00363.x.

[77] Seber S, Ucak S, Basat O, Altuntas Y. The effect of dual PPAR alpha/ gamma stimulation with combination of rosiglitazone and fenofibrate on metabolic parameters in type 2 diabetic patients. Diabetes Res Clin Pract 2006;71:52-58. doi:10.1016/j.diabres.2005.05.009.

[78] Jain MR, Giri SR, Trivedi C, Bhoi B, Rath A, Vanage G, et al. Saroglitazar, a novel PPARa/Y agonist with predominant PPARa activity, shows lipidlowering and insulin-sensitizing effects in preclinical models. Pharmacol Res Perspect 2015;3:e00136. doi:10.1002/prp2.136.

[79] Kumar DP, Caffrey R, Marioneaux J, Santhekadur PK, Bhat M, Alonso C, et al. The PPAR a/Y agonist saroglitazar improves insulin resistance and steatohepatitis in a diet induced animal model of nonalcoholic fatty liver disease. Sci Rep 2020;10:9330. doi:10.1038/s41598-020-66458-z.

[80] Hassan NF, Nada SA, Hassan A, El-Ansary MR, Al-Shorbagy MY, Abdelsalam RM. Saroglitazar deactivates the hepatic LPS/TLR4 signaling pathway and ameliorates adipocyte dysfunction in rats with high-fat emulsion/LPS model-induced non-alcoholic steatohepatitis. Inflammation 2019;42:10561070. doi:10.1007/s10753-019-00967-6.

[81] Jain MR, Giri SR, Bhoi B, Trivedi C, Rath A, Rathod R, et al. Dual PPARa/Y agonist saroglitazar improves liver histopathology and biochemistry in experimental NASH models. Liver Int 2018;38:1084-1094. doi:10.1111/ liv. 13634 .

[82] Caffrey R, Marioneaux J, Santhekadur P, Bedossa P, Philip B, Giri S, et al. Saroglitazar treatment prevents NASH, eliminates hepatocyte ballooning, and significantly improves serum LFTs, lipids and insulin resistance in DIAMOND (tm) mice compared to pioglitazone benchmark. J Hepatol 2018;68:S578-S579. doi:10.1016/S0168-8278(18)31416-8.

[83] Late-Breaking Abstracts - Presented at the 70th Annual Meeting of the American Association for the Study of Liver Diseases: The Liver Meeting ${ }^{\mathrm{TM}}$ 2019. Hepatology 2019;70:1477A-1501A. doi:10.1002/hep.31033.

[84] Staels B, Rubenstrunk A, Noel B, Rigou G, Delataille P, Millatt L], et al. Hepatoprotective effects of the dual peroxisome proliferator-activated receptor alpha/delta agonist, GFT505, in rodent models of nonalcoholic fatty liver disease/nonalcoholic steatohepatitis. Hepatology 2013;58:19411952. doi:10.1002/hep.26461.

[85] Ratziu V, Harrison SA, Francque S, Bedossa P, Lehert P, Serfaty L, et al. Elafibranor, an agonist of the peroxisome proliferator-activated receptor-a and $-\delta$, induces resolution of nonalcoholic steatohepatitis without fibrosis worsening. Gastroenterology 2016;150:1147-1159.e5. doi:10.1053/j. gastro.2016.01.038.

[86] Lefere S, Puengel T, Hundertmark J, Penners C, Frank AK, Guillot A, et al. Differential effects of selective- and pan-PPAR agonists on experimental steatohepatitis and hepatic macrophages ${ }^{\square}$. J Hepatol 2020;73:757-770. doi:10.1016/j.jhep.2020.04.025.

[87] Paton CM, Ntambi JM. Biochemical and physiological function of stearoylCoA desaturase. Am J Physiol Endocrinol Metab 2009;297:E28-E37. doi:10.1152/ajpendo.90897.2008.

[88] Iruarrizaga-Lejarreta M, Varela-Rey M, Fernández-Ramos D, MartínezArranz I, Delgado TC, Simon J, et al. Role of Aramchol in steatohepatitis and fibrosis in mice. Hepatol Commun 2017;1:911-927. doi:10.1002/ hep4.1107.

[89] Safadi R, Konikoff FM, Mahamid M, Zelber-Sagi S, Halpern M, Gilat T, et al. The fatty acid-bile acid conjugate Aramchol reduces liver fat content in patients with nonalcoholic fatty liver disease. Clin Gastroenterol Hepatol 2014;12:2085-2091.e1. doi:10.1016/j.cgh.2014.04.038.

[90] Mossanen JC, Krenkel O, Ergen C, Govaere O, Liepelt A, Puengel T, et al. Chemokine ( $\mathrm{C}-\mathrm{C}$ motif) receptor 2-positive monocytes aggravate the early phase of acetaminophen-induced acute liver injury. Hepatology 2016;64:1667-1682. doi:10.1002/hep.28682

[91] Krenkel O, Puengel T, Govaere O, Abdallah AT, Mossanen JC, Kohlhepp $\mathrm{M}$, et al. Therapeutic inhibition of inflammatory monocyte recruitment reduces steatohepatitis and liver fibrosis. Hepatology 2018;67:1270-1283. doi:10.1002/hep.29544.

[92] Marra F, Tacke F. Roles for chemokines in liver disease. Gastroenterology 2014;147:577-594.e1. doi:10.1053/j.gastro.2014.06.043.

[93] Friedman SL, Ratziu V, Harrison SA, Abdelmalek MF, Aithal GP, Caballeria $\mathrm{J}$, et al. A randomized, placebo-controlled trial of cenicriviroc for treatment of nonalcoholic steatohepatitis with fibrosis. Hepatology 2018;67:17541767. doi:10.1002/hep.29477.

[94] Ratziu V, Sanyal A, Harrison SA, Wong VW, Francque S, Goodman Z, et al. Cenicriviroc treatment for adults with nonalcoholic steatohepatitis and fibrosis: Final analysis of the phase $2 \mathrm{~b}$ CENTAUR study. Hepatology 2020;72(3):892-905. doi:10.1002/hep.31108.

[95] Anstee QM, Neuschwander-Tetri BA, Wong VW, Abdelmalek MF, Younossi 
ZM, Yuan J, et al. Cenicriviroc for the treatment of liver fibrosis in adults with nonalcoholic steatohepatitis: AURORA Phase 3 study design. Contemp Clin Trials 2020;89:105922. doi:10.1016/j.cct.2019.105922.

[96] Kaji N, Takagi Y, Matsuda S, Takahashi A, Fujio S, Asai F. Effects of liraglutide on metabolic syndrome in WBN/Kob diabetic fatty rats supplemented with a high-fat diet. Animal Model Exp Med 2020;3:62-68. doi:10.1002/ ame2.12106.

[97] Armstrong MJ, Hull D, Guo K, Barton D, Hazlehurst JM, Gathercole LL, et al. Glucagon-like peptide 1 decreases lipotoxicity in non-alcoholic steatohepatitis. J Hepatol 2016;64:399-408. doi:10.1016/j.jhep.2015.08.038.

[98] Armstrong MJ, Gaunt P, Aithal GP, Barton D, Hull D, Parker R, et al. Liraglutide safety and efficacy in patients with non-alcoholic steatohepatitis (LEAN): a multicentre, double-blind, randomised, placebo-controlled phase 2 study. Lancet 2016;387:679-690. doi:10.1016/S0140-6736(15)00803-X

[99] Nauck MA, Jensen TJ, Rosenkilde C, Calanna S, Buse JB. Neoplasms reported with liraglutide or placebo in people with type 2 diabetes: Results from the LEADER randomized trial. Diabetes Care 2018;41:1663-1671. doi: $10.2337 / \mathrm{dc} 17-1825$.

[100] Funch D, Mortimer K, Ziyadeh NJ, Seeger JD, Li L, Norman H, et al. Liraglutide use and evaluation of pancreatic outcomes in a US commercially insured population. Diabetes Obes Metab 2019;21:1837-1848. doi:10.1111/dom.13739.

[101] O'Neil PM, Birkenfeld AL, McGowan B, Mosenzon O, Pedersen SD, Wharton $\mathrm{S}$, et al. Efficacy and safety of semaglutide compared with liraglutide and placebo for weight loss in patients with obesity: a randomised, doubleblind, placebo and active controlled, dose-ranging, phase 2 trial. Lancet 2018;392:637-649. doi:10.1016/S0140-6736(18)31773-2.

[102] Newsome P, Francque S, Harrison S, Ratziu V, Van Gaal L, Calanna S, et al. Effect of semaglutide on liver enzymes and markers of inflammation in subjects with type 2 diabetes and/or obesity. Aliment Pharmacol Ther 2019;50:193-203. doi:10.1111/apt.15316.

[103] Díaz-Alvarez L, Ortega E. The many roles of galectin-3, a multifaceted molecule, in innate immune responses against pathogens. Mediators Inflamm 2017;2017:9247574. doi:10.1155/2017/9247574

[104] Dong R, Zhang M, Hu Q, Zheng S, Soh A, Zheng Y, et al. Galectin-3 as a novel biomarker for disease diagnosis and a target for therapy (Review). Int J Mol Med 2018;41:599-614. doi:10.3892/ijmm.2017.3311.

[105] Traber PG, Zomer E. Therapy of experimental NASH and fibrosis with galectin inhibitors. PLoS One 2013;8:e83481. doi:10.1371/journal. pone.0083481.

[106] Harrison SA, Marri SR, Chalasani N, Kohli R, Aronstein W, Thompson GA, et al. Randomised clinical study: GR-MD-02, a galectin-3 inhibitor, vs. placebo in patients having non-alcoholic steatohepatitis with advanced fibrosis. Aliment Pharmacol Ther 2016;44:1183-1198. doi:10.1111/apt.13816.

[107] Iacobini C, Menini S, Ricci C, Blasetti Fantauzzi C, Scipioni A, et al. Galectin-3 ablation protects mice from diet-induced NASH: a major scavenging role for galectin-3 in liver. J Hepatol 2011;54:975-983. doi: 10.1016/j. ing role for galectin-3

[108] Chalasani N, Abdelmalek MF, Garcia-Tsao G, Vuppalanchi R, Alkhouri N, Rinella $\mathrm{M}$, et al. Effects of belapectin, an inhibitor of galectin-3, in patients with nonalcoholic steatohepatitis with cirrhosis and portal hypertension. Gastroenterology 2020;158:1334-1345.e5. doi:10.1053/j.gastro.2019.11.296.

[109] Barreyro FJ, Holod S, Finocchietto PV, Camino AM, Aquino JB, Avagnina $A$, et al. The pan-caspase inhibitor Emricasan (IDN-6556) decreases liver injury and fibrosis in a murine model of non-alcoholic steatohepatitis. Liver injury and fibrosis in a murine model of non-alco

[110] Frenette CT, Morelli G, Shiffman ML, Frederick RT, Rubin RA, Fallon MB, et al. Emricasan improves liver function in patients with cirrhosis and high model for end-stage liver disease scores compared with placebo. Clin Gas troenterol Hepatol 2019;17:774-783.e4. doi:10.1016/j.cgh.2018.06.012.

[111] Garcia-Tsao G, Bosch J, Kayali Z, Harrison SA, Abdelmalek MF, Lawitz E, et al. Randomized placebo-controlled trial of emricasan for non-alcoholic steatohepatitis-related cirrhosis with severe portal hypertension. J Hepatol 2020;72:885-895. doi:10.1016/j.jhep.2019.12.010.

[112] Harrison SA, Goodman Z, Jabbar A, Vemulapalli R, Younes ZH, Freilich $\mathrm{B}$, et al. A randomized, placebo-controlled trial of emricasan in patients with NASH and F1-F3 fibrosis. J Hepatol 2020;72:816-827. doi:10.1016/j. jhep.2019.11.024.

[113] Younossi ZM, Stepanova M, Lawitz E, Charlton M, Loomba R, Myers RP, et al. Improvement of hepatic fibrosis and patient-reported outcomes in nonalcoholic steatohepatitis treated with selonsertib. Liver Int 2018;38:18491859. doi:10.1111/liv.13706.
alcoholic steatohepatis treated

[114] Jayakumar S, Middleton MS, Lawitz EJ, Mantry PS, Caldwell SH, Arnold H, et al. Longitudinal correlations between MRE, MRI-PDFF, and liver histology in patients with non-alcoholic steatohepatitis: Analysis of data from a phase II trial of selonsertib. J Hepatol 2019;70:133-141. doi:10.1016/j. jhep.2018.09.024.

[115] Harrison SA, Wong VW, Okanoue T, Bzowej N, Vuppalanchi R, Younes Z, et al. Selonsertib for patients with bridging fibrosis or compensated cirrhosis due to NASH: Results from randomized phase III STELLAR trials. J Hepatol 2020;73:26-39. doi:10.1016/j.jhep.2020.02.027.

[116] Rajasekaran M, Locke KW, Parsons CL. MN-001, a novel oral anti-inflammatory agent, suppresses bladder hyperactivity in a rat model. BJU Int 2006;98:430-434. doi:10.1111/j.1464-410X.2006.06274.x

[117] Matsuda K, Gutierrez J, Hassanein T, Iwaki Y. The anti-fibrotic agent, tipelukast (MN-001) reduces serum triglyceride significantly in non-alcoholic steatohepatitis and non-alcoholic fatty liver disease patients with hypertriglyceridemia after 4 weeks of treatment, an interim analysis of ongoing clinical trial, MN-001-NATG-201. J Hepatol 2018;68:S586. doi:10.1016/ S0168-8278(18)31433-8.

[118] Siebers N, Palmer M, Silberg DG, Jennings L, Bliss C, Martin PT. Absorption, distribution, metabolism, and excretion of $\left[{ }^{14} \mathrm{C}\right]$-volixibat in healthy men: Phase 1 open-label study. Eur J Drug Metab Pharmacokinet 2018;43:91-101. doi:10.1007/s13318-017-0429-7.

[119] Tiessen RG, Kennedy CA, Keller BT, Levin N, Acevedo L, Gedulin B, et al. Safety, tolerability and pharmacodynamics of apical sodium-dependent bile acid transporter inhibition with volixibat in healthy adults and patients with type 2 diabetes mellitus: a randomised placebo-controlled trial. BMC Gastroenterol 2018:18:3 doi:10.1186/s12876-017-0736-0.

[120] Newsome PN, Palmer M, Freilich B, Sheikh MY, Sheikh A, Sarles H, et al. Volixibat in adults with non-alcoholic steatohepatitis: 24 -week interim analysis from a randomized, phase II study. J Hepatol 2020;73:231-240. doi:10.1016/j.jhep.2020.03.024

[121] Hou X, Xu S, Maitland-Toolan KA, Sato K, Jiang B, Ido $Y$, et al. SIRT1 regulates hepatocyte lipid metabolism through activating AMP-activated protein kinase. J Biol Chem 2008;283:20015-20026. doi:10.1074/jbc. M802187200.

[122] Banerjee ], Bruckbauer A, Zemel MB. Activation of the AMPK/Sirt1 pathway by a leucine-metformin combination increases insulin sensitivity in way by a leucine-metformin combination increases insulin sensitivity in skeletal muscle, and stimulates glucose and lipid metabolism and increas-
es life span in Caenorhabditis elegans. Metabolism 2016;65:1679-1691. es life span in Caenorhabditis elegans.
doi:10.1016/j.metabol.2016.06.011.

[123] Fu L, Bruckbauer A, Li F, Cao Q, Cui X, Wu R, et al. Interaction between metformin and leucine in reducing hyperlipidemia and hepatic lipid accumulation in diet-induced obese mice. Metabolism 2015;64:1426-1434. doi:10.1016/j.metabol.2015.07.006.

[124] Bruckbauer A, Banerjee ], Fu L, Li F, Cao Q, Cui X et al A combination of leucine, metformin, and sildenafil treats nonalcoholic fatty liver tion of leucine, metformin, and sildenafil treats nonalcoholic fatty liver doi:10.1155/2016/9185987.

[125] Chalasani N, Vuppalanchi R, Rinella M, Middleton MS, Siddiqui MS, Barritt AS4th, et al. Randomised clinical trial: a leucine-metformin-sildenafil combination (NS-0200) vs placebo in patients with non-alcoholic fatty liver disease. Aliment Pharmacol Ther 2018;47:1639-1651. doi:10.1111/ apt.14674. 